\title{
Performance Chronicles of Multicast Routing Protocol in Wireless Sensor Network
}

\author{
Nandini G \\ Research Scholar \\ Visvesvaraya Technological University \\ Belagavi, Karnataka, India
}

\author{
J. Anitha \\ Prof.: Dept. of Computer Science \& Engineering \\ Dayananda Sagar Academy of Technology \& Management \\ Bengaluru, Karnataka, India
}

\begin{abstract}
Routing protocol in wireless sensor network (WSN) has always been a frequently adopted topic of research in WSN owing to many unsolved issues in it. This paper discusses about the multicast routing protocols in WSN and briefs up different forms of standard research contribution as well as significant recent research techniques toward leveraging the performance of multicast routing. The paper then discusses the beneficial factor and limiting factor in existing multicast techniques and highlights the research gap in this. In order to overcome the research gap, a novel architecture to address the optimization as a cost minimization problem associated with multicast routing in WSN is proposed. This paper contributes to show a present scenario of multicast routing performance in WSN and thereby assists the readers about the possible direction of future with clear visualization of system architecture.
\end{abstract}

Keywords-Complexity; multicast routing techniques; overhead; optimization; routing protocol; wireless sensor network

\section{INTRODUCTION}

A Wireless Sensor Network (WSN) made up of an interconnected network of a sensor node which is capable of sensing an environment data, process it, and forward it to a destination node called sink node typically as reverse multicast (many to one), which is further connected to gateways to transfer data to the monitoring unit. There are wide range of application of WSN, e.g. habitat monitoring (animal wellbeing), industrial monitoring, healthcare, structural health monitoring (SHM), etc. [1]-[3]. A sensor node has a very less computational capability and has highly limited availability of memory and battery lifetime [4]. Because of these inherent characteristics of WSN, it is quite a difficult task to perform communication. The primary reason is non-applicability of global addressing policies to sensor motes and it generates overhead to maintain node ID [5]. It will eventually mean that conventional IP-based approaches cannot be implemented in sensor network. The second reason is flow of captured data which is from multiple sensor nodes (also called as clusterheads) to a single (or sometimes multiple) receiver called as base station/sink node, which is bit different than other conventional network system. A sensor node has critical need of resource management as they have limited availability of resources and storage priviledge. The third reason is of dynamic topology due to various reasons such as node mobility, link failures, etc. Maximum application considers static states of nodes and it retains permission for mobile nodes to be base station only in few cases. Because of this reason, the existing routing algorithms find quite hard to come up with communication requirements [6]-[9]. This paper has discussed various types of routing techniques where a special emphasis is given on multicast routing. Basically, multicasting operation leads to forwarding of same message to multiple sensors at a same interval of time [10]. It highly assists in group communication and its applications ranges from defence and military communication system which require covert transmission of message over multiple locations. One interesting fact about multicast routing is that they were originally designed for mobile adhoc networks but it doesn't stop us from using it in sensor networks too. The multicast routing protocols in WSN is always studied with respect to reactive protocols (PUMA [11], MAODV [12], ODMRP [13]), proactive protocols (ALMA [14], OBAMP [15], ALMA-H [14]), and hybrid protocols. Further discussion of existing multicast routing can be seen is existing reviews, e.g. [16]-[18]. It allows the route to stay active until the message doesn't reach its destination. Although multicast routing claims to reduce message overhead but it suffers from maximum delay in exploring stabilized routes. There are presence of multiple review paper, which has discussed about the strength and weakness of various categories of routing protocol in wireless sensor network in perspective of routing [19], load balancing [20], security [21], energy efficiency [22], etc. We find that emphasis of review papers are more in routing protocols and energy efficiency problems. Even in routing protocols, majority of the review paper either discusses the prior work with respect to security or energy. Hence, we find very less effective review papers are there which balance between essentials of multicast routing, the effectiveness of existing literature and highlights of best possible way to carry out future research direction.

Hence, we will like to make a difference by reviewing significant literatures in multicast routing used in sensor network, explored research gaps in recent research contribution, and highlighted advantages and limitation of existing studies. Finally, we propose a possible architecture to defeat research gap and bring contribution to effective multicast routing in wireless sensor network. Section II discusses about the taxonomies of many routing standards in WSN followed by discussion of Multicast routing essentials in Section III. The discussion of existing research work towards upgrading the performance of multicast routing protocol is given in Section IV. Section V highlights the research gap 
while Section VI discusses about the proposed line of research. Section VII summarizes the entire paper.

\section{TAXONOMY OF Routing PROTOCOLS IN WSN}

There are various classification types in understanding the taxonomies of routing protocol in wireless sensor network. This section discusses about the several types of routing standards in WSN. Basically, the communication mechanism in wireless sensor network is very much different compared to other forms of wireless communication system, e.g. adhoc network. The numbers of involvement of nodes are quite higher as compared to that of other forms of networks. There is also a higher dependency of infrastructure for the sensor node to perform communication. Moreover the nature of the links created in wireless sensor network are highly unreliable in nature and do have multiple energy constraints. Basically, the routing procedures of wireless sensor networks (WSNs) are five types which are with respect to, i.e. 1) initialization of communication; 2) path establishment; 3) network structure; 4) protocol operation; and 5) next hop selection. Elaborated discussion of this can be found in [6]-[9]. The initialization of the communication factor is further studied with respect to source and destination node. The path establishment factor is classified into three types, i.e. proactive, reactive, and hybrid. The classification based on network structure are of three types, i.e. flat, hierarchical (or cluster-based) and locationbased. Routing protocols based on protocol operations are of 4 types, i.e. multipath, query based, negotiation based, and QoS based. The routing protocols based on next hop selection are again classified into broadcast based, location based, content based, and probabilistic based. The taxonomy is shown in Fig. 1.

Fig. 1 shows the generalized taxonomy of routing paths in WSN. However, this is less referred classification techniques in frequent routing approaches in same field. Hence, Fig. 2 shows the frequently used taxonomy of routing protocols which are considered in existing studies towards routing and is emphasized more than the generalized taxonomy.

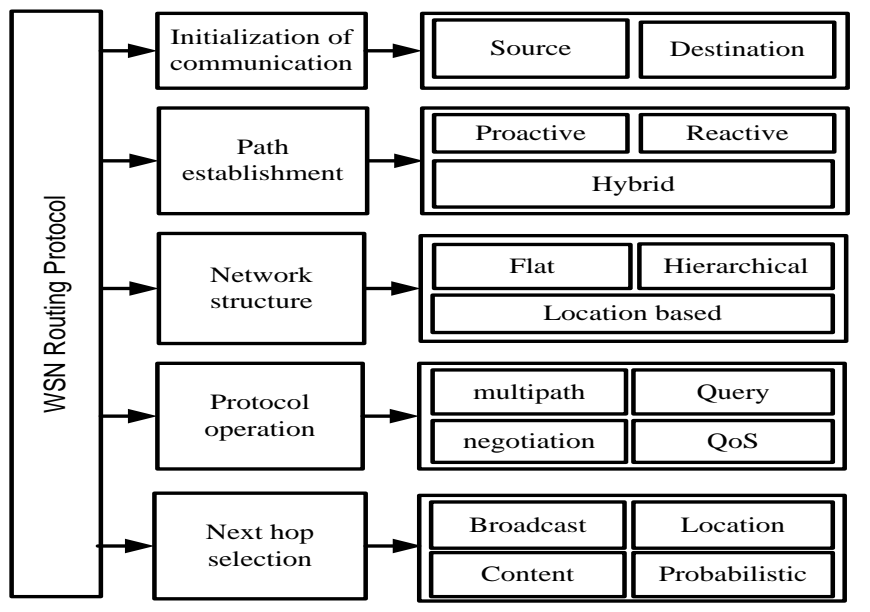

Fig. 1. General taxonomy of routing protocols in WSN.

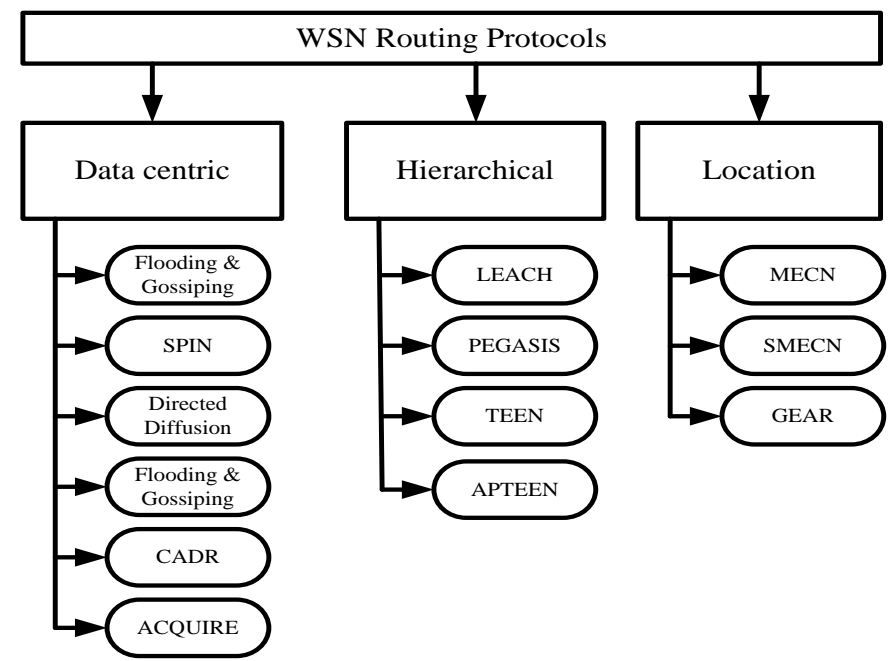

Fig. 2. Frequently used taxonomy of routing protocols in WSN.

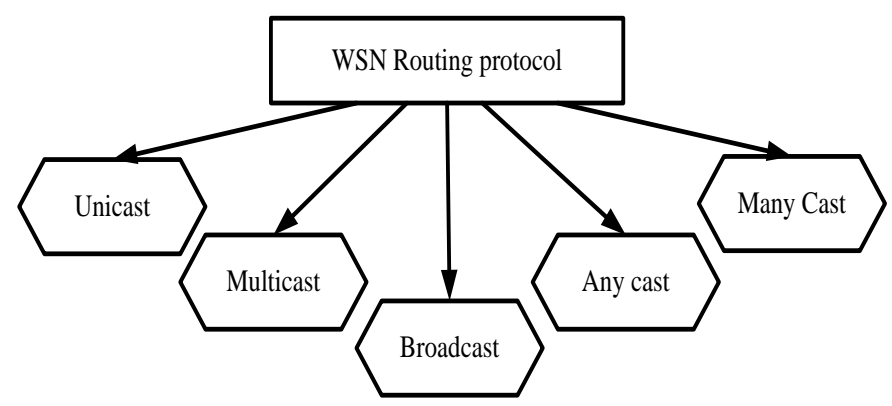

Fig. 3. Routing protocols based on transmission in WSN.

According to this taxonomy, the standard routing protocols are classified into three types, i.e. Data centric protocols, hierarchical protocols, and location based protocols. The data centric protocols works on query processing in order to minimize the retransmission process [23]. Hierarchical routing techniques works on the principle of clustering and is mainly intended to minimize the energy involved in performing communication and data aggregation [24]. Location based protocols are used for using the position-based data of node in order to perform data relaying to the destination node. The distance to adjacent node is estimated using signal strength in this technique [25]. Routing protocols are given also classified based on mode of transmission (is represented in Fig. 3) i.e. unicast, multicast, broadcast, any cast, and many cast.

\section{Multicast Routing Protocols}

The meaning of multicast is to forward the control message from one source node to many destination nodes in wireless sensor network. In case of utilization of multiple sinks, multicast mechanism is highly beneficial as it forwards the similar reports to all sinks. The following Fig. 4 represents the mechanism of multicast routing. 


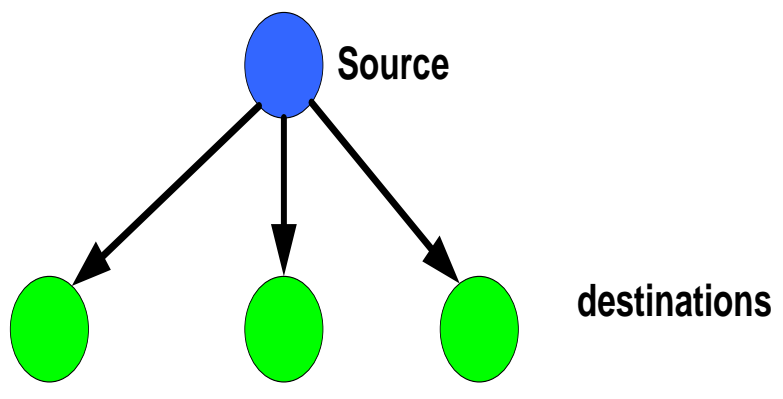

Fig. 4. Mechanism of multicast routing in WSN.

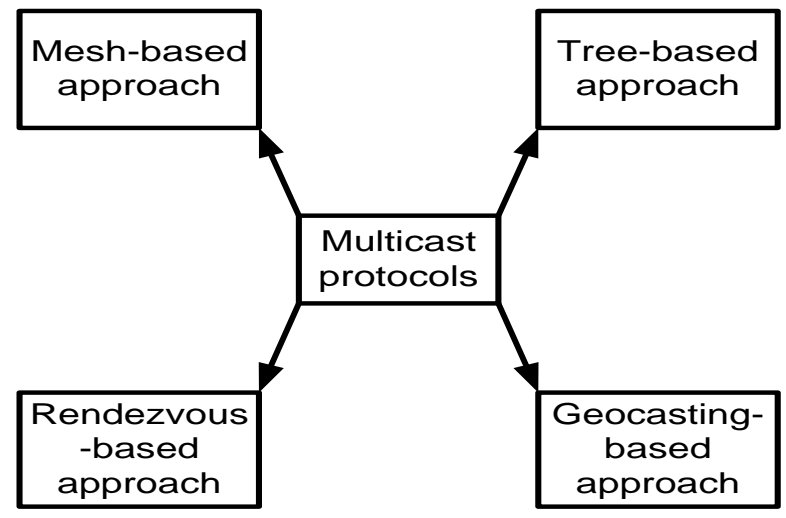

Fig. 5. Classification of multicast routing in in WSN.

The prime motive of adopting multicast routing mechanism is to minimize the channel capacity over the wireless links applicable for different sensory application that uses replication of data, allocation of jobs, and transmission of specific instruction to particular clusters of sensors etc. One of the good examples of multicast routing in wireless sensor network (WSN) is smoke/fire in infrastructure detection system. In such application, probability of infrastructure to catch fire is computed. The thermal sensor senses the raw signal of smoke/fire as well as it also tracks the changes in temperature to confirm the emergency situation of fire. It than transmits the information to all neighborhood sensors which are positioned in different part of the infrastructure in order to fine tune the rate of sampling fire data. This data is further compared with threshold limit to confirm the emergence of situation and positive case will let the data to be automatically forward as an alarm system to nearby fire station or hospital. It was also seen that there were maximized usage of the unicast routing protocols in wireless sensor network owing to multiple benefits, e.g. supportability to work in resource constraint environment, adapts well to dynamic environments too. However, it was not enough to cater up the need of large scale environment. Hence, multicast routing provides better scalability and is essentially studied into four different types of it, i.e. tree-based approach, Geocasting-based approach, Rendezvous-based approach, and Mesh-based approach as shown in Fig. 5

Based on the different techniques introduced by various researchers in past, the multicast routing protocols in WSNs are basically classified into following:

\section{A. Tree-Based Technique}

Using graph theory, this technique is used for designing direct route formulation independent of any loops in order to provide a shortest routes in wireless sensor network. It also allows a maximum flexibility for leaving or participating in the network. This technique is also depends on multiple attributes e.g. quality of link, channel capacity, latency, hop counts, etc. The biggest problem of tree-based multicast routing protocol is that in case of any form failure of the link that the entire edges of the tree gets negatively affected.

\section{B. Geocasting-Based Technique}

This forms of communication mechanism is highly restricted to the recipient sensors as the delivery of the data packets takes place only to a group of sensor positioned in a particular geographical area. The group management of the geocast is represented using its respective location. This routing technique is quite ideal for heterogeneous wireless sensor network however it is still shrouded with certain problems of scalability. Hence, this routing technique is suitable for small scale network only.

\section{Mesh-Based Technique}

This routing technique formulates mesh structure for all the group members for the purpose of achieving connection to all the member nodes with each other. The system accomplishes mesh formulation as well as route discovery using broadcasting mechanism. Mesh-based multicasting routing technique is found to highly support mobility of the nodes. It also has the potential to visualize the traffic-related issues. It is better than tree-based technique as if any link undergoes any form of failures that entire network is not affected.

\section{Rendezvous-Based Technique}

This technique consider a specific sensor node to be acting as rendezvous point which is responsible to perform aggregation of the fused data from different member node. This fused data are further transmitted to the base station. However, this type of technique is also found to possess limitation of massive time consumption for processing the message and thereby incur a big damage to the entire in case of failure for rendezvous point.

Multicast routing is essentially made for minimizing the energy consumption in the network along with an assurity of transmission of minimum replicated message over the network. However, there are various impediment to successfully implement the above stated conventional routing protocols due to energy constraints and limited computational capability of a sensor node. Apart from the above mentioned classification of multicast routing protocols, we also discuss the classification based on standard research contribution towards this communication mechanism. The research work was focused on evolving multicast routing for catering up emergency-based applications in sensor network with minimal energy consumption and optimal usage of channel capacity in presence of multiple sensor nodes as destination. 


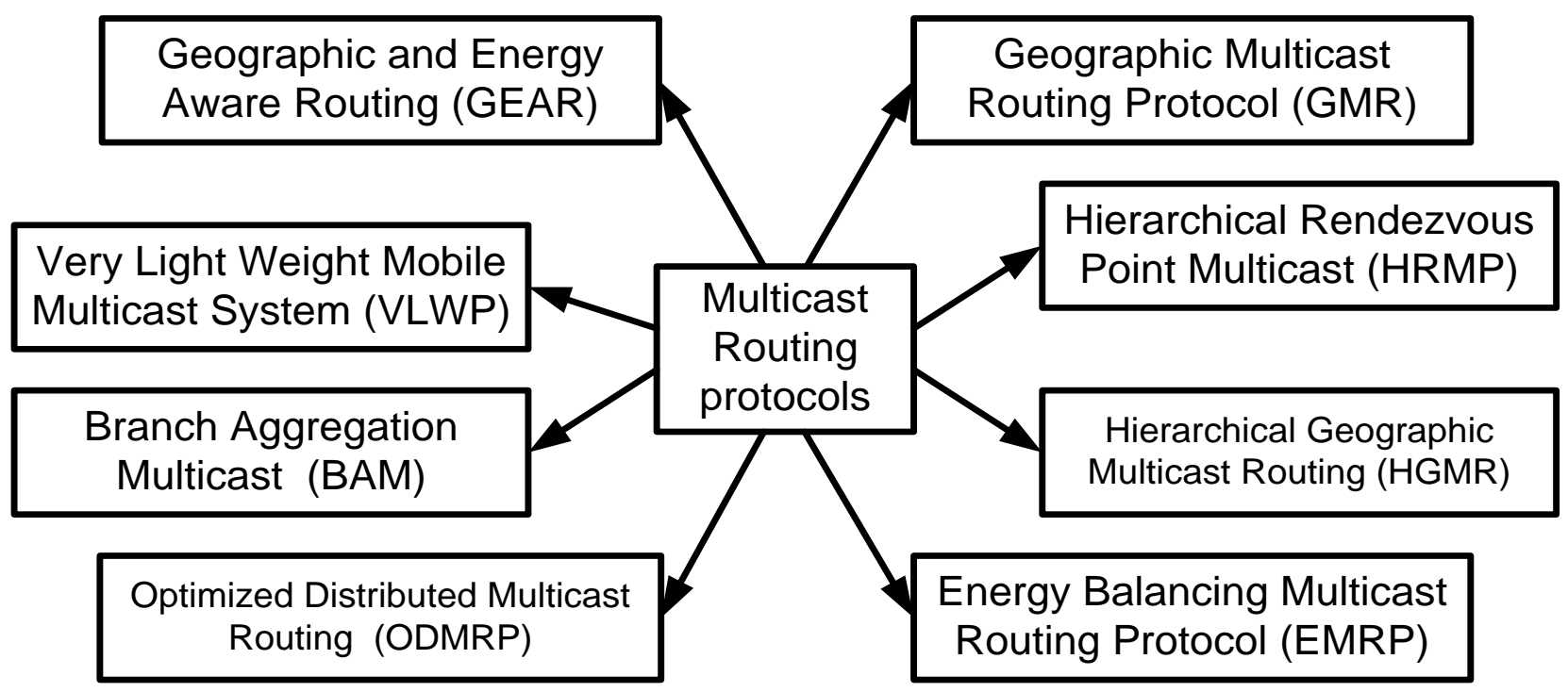

Fig. 6. Standard multicast routing in in WSN.

Fig. 6 shows the classification of standard multicast routing protocol in wireless sensor network.

\section{E. Geographic and Energy Aware Routing}

The main purpose of this protocol is to use geographically informed neighbor nodes as well as energy efficient nodes in order to perform routing.

\section{F. Very Light Weight Mobile Multicast System}

This routing scheme uses a unique ID assigned to sensor that consists of personal identity and identity of group of multicast. Using flooding technique, it performs routing. It also uses unicast routing between node and base station. Interesting, it uses multicast for the reverse communication process i.e. from base station to sensor node.

\section{G. Lightweight Protocol forMulticast}

This routing technique is meant to utilize least resources and it considers mobile sinks whose position is monitored using track and transmit scheme. It checks for new position of base station in order to complete data aggregation.

\section{H. Branch Aggregation Multicast Protocol}

This protocol emphasizes branch in order to complete routing and is of two type i.e. single and multihop aggregation technique.

\section{Optimized Distributed Multicast Routing protocol (ODMRP)}

It works on the principle of constructing distributed multicast tree with shortest route right from sensor node to base station. This routing technique considers multiple base station using tree technique using multicast communication.

\section{J. Geographic Multicast Routing Protocol}

It is meant to support distributed routing where the protocol provide an ID to each packet leading to the destination of multicast routes. It also uses greedy approach for forming routes.

\section{K. Hierarchical Rendezvous Point Multicast}

The prime motive of this multicast routing technique is to minimize overhead caused due to encoding process in using location based routing approaches. This is carried out by developing a hierarchy that classifies the network based on multicast clusters. It further minimizes the sizes of clusters which are controlled by a router. In order to minimize the dependency as well as to perform maintenance of router, this protocol uses geographic hashing with mobility factor. It also uses rendezvous point without any extra resource consumption.

\section{Hierarchical Geographic Multicast Routing Protocol}

This protocol is formed by integrating geographic routing with hierarchical rendezvous point multicasting. The protocol performs decomposition of multicast group to come up with smaller groups which can be managed easily with an aid of geographic routing protocol. An overlay tree is constructed by the source node that connects a source node to access point and access point to member node using another tree. The technique uses Hierarchical Rendezvous Point Multicast in order to perform data transmission using unicast approach.

\section{Energy Balancing Multicast Routing Protocol}

The motive of this routing technique is to retain better form of balance in battery lifetime of a node. The technique ensures no alteration in the route until and unless there is no significant change in topology. This work was done to improve the network lifetime. The scheme is more emphasizing on energy allocation schemes in order to maintain a higher degree of balance.

The routing standards discussed above have both advantages as well as limitation, which is further highlighted in Tables 1 and 2 .

TABLE I. Characteristics of Multicasting Routing Protocols in WSN 


\begin{tabular}{|c|c|c|c|}
\hline Name & Year & Advantage & Limitation \\
\hline $\begin{array}{l}\text { Geographic \& Energy Aware Routing } \\
\text { [26] }\end{array}$ & 2001 & $\begin{array}{l}\text {-Better energy efficiency even } \\
\text {-Delay minimization capabilities }\end{array}$ & $\begin{array}{l}\text {-Limited scalability } \\
\text {-Poor power management } \\
\text {-Prone to Sybil attack }\end{array}$ \\
\hline $\begin{array}{l}\text { Very Light Weight Mobile Multicast } \\
\text { System (VLMP) [27] }\end{array}$ & 2003 & $\begin{array}{l}\text {-Supports mobility } \\
\text {-Supports fault tolerance }\end{array}$ & $\begin{array}{l}\text {-Maximum delay \& overhead } \\
\text {-Less scalable } \\
\text {-Not energy efficient }\end{array}$ \\
\hline $\begin{array}{l}\text { Lightweight Protocol for Multicast } \\
\text { (LWMP) [27] }\end{array}$ & 2005 & $\begin{array}{l}\text {-High packet delivery ratio } \\
\text {-Supports implementing in both static/mobile } \\
\text { networks } \\
\text {-Ensure proximity of data to sink }\end{array}$ & $\begin{array}{l}\text {-High overhead } \\
\text {-High energy consumption } \\
\text {-Less scalable }\end{array}$ \\
\hline $\begin{array}{l}\text { Branch Aggregation Multicast } \\
\text { Protocol (BAM) [28] }\end{array}$ & 2005 & -Minimize bandwidth & $\begin{array}{l}\text {-Less scalable } \\
\text {-Doesn't support real-time communication } \\
\text {-Not compatible with event-driven protocols }\end{array}$ \\
\hline $\begin{array}{l}\text { Optimized Distributed Multicast } \\
\text { Routing protocol (ODMRP) [29] }\end{array}$ & 2006 & $\begin{array}{l}\text {-Supports scalability } \\
\text {-Support multi-sink architecture }\end{array}$ & $\begin{array}{l}\text {-Overhead due to encoding } \\
\text {-Maximized delay }\end{array}$ \\
\hline $\begin{array}{l}\text { Geographic Multicast Routing } \\
\text { Protocol (GMR) [30] }\end{array}$ & 2006 & $\begin{array}{l}\text {-Support proper bandwidth usage } \\
\text {-Energy efficient }\end{array}$ & $\begin{array}{l}\text {-Suffers from scalability issue } \\
\text {-Encoding overhead }\end{array}$ \\
\hline $\begin{array}{l}\text { Hierarchical Rendezvous Point } \\
\text { Multicast (HRPM) [31] }\end{array}$ & 2006 & $\begin{array}{l}\text {-Minimize encoding overhead } \\
\text {-Less delay }\end{array}$ & $\begin{array}{l}\text {-Energy consumption } \\
\text {-Consumes bandwidth }\end{array}$ \\
\hline $\begin{array}{l}\text { Hierarchical Geographic Multicast } \\
\text { Routing Protocol (HGMR) [32] }\end{array}$ & 2007 & $\begin{array}{l}\text {-Energy efficient } \\
\text {-Enhanced scalability } \\
\text {-Minimal delay }\end{array}$ & $\begin{array}{l}\text {-Prone to noise } \\
\text {-Lower data efficiency }\end{array}$ \\
\hline $\begin{array}{l}\text { Energy Balancing Multicast Routing } \\
\text { Protocol (EMRP) [33] }\end{array}$ & 2008 & -Energy balancing capability & $\begin{array}{l}\text {-More data consumption as it includes more nodes to data } \\
\text { delivery }\end{array}$ \\
\hline
\end{tabular}

TABLE II. EFFECTIVENESS OF MULTICASTING ROUTING PROTOCOLS IN WSN [ REPRESENTS SCORE OF RESPECTIVE DATA]

\begin{tabular}{|c|c|c|c|c|c|c|}
\hline Multicast Routing Protocol & Lifetime & Delay & Complexity & Overhead & Throughput & Scalability \\
\hline GEAR [26] & $\leftrightarrow \leftrightarrow$ & 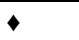 & $\bullet$ & $\leftrightarrow$ & $\leftrightarrow 4$ & 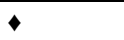 \\
\hline VLMP [27] & 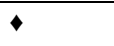 & 444 & 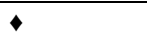 & $4+4$ & 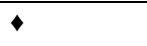 & 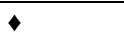 \\
\hline LWMP [27] & 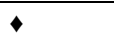 & 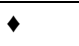 & $\leftrightarrow$ & ४४४४ & 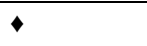 & 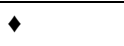 \\
\hline BAM [28] & $\leftrightarrow 4$ & 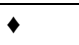 & $\leftrightarrow$ & $\bullet$ & 444 & $\leftrightarrow 4$ \\
\hline ODMRP [29] & $\leftrightarrow \leftrightarrow$ & 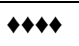 & $\leftrightarrow \leftrightarrow \bullet$ & ४४४४ & 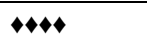 & $\leftrightarrow \leftrightarrow$ \\
\hline GMR [30] & 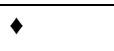 & 444 & 444 & $44+4$ & $44+4$ & + \\
\hline HRPM [31] & 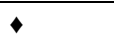 & $\leftrightarrow \leftrightarrow$ & $\leftrightarrow$ & 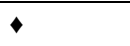 & 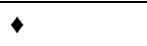 & $\leftrightarrow \leftrightarrow$ \\
\hline HGMR [32] & $\leftrightarrow 4$ & 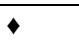 & 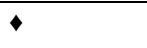 & 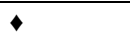 & 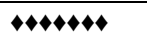 & 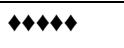 \\
\hline EMRP [33] & $\leftrightarrow$ & 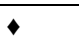 & $\leftrightarrow$ & $4+4$ & 444 & $\leftrightarrow$ \\
\hline
\end{tabular}

\section{EXISTING RESEARCH WORK}

This section discusses about the recent research work in the direction of the multicast routing protocol in wireless sensor network.
Piechowiak et al. [34] have recently published a paper discussing about the techniques used by different researchers toward formulating multicast routing protocol in wireless sensor network. The author have also discussed about the 
network modelling used in topology control of sensor network followed simulation outcomes.

Another recent study towards enhancing the performance of multicast routing was introduced by Thenral and Sikamani [35]. The techniques addresses the overhead in communication problem in wireless mesh network and introduce an angular concept of routing. A condition of intermediate node selection based on $60 \%$ angle estimation is discussed in this paper. The study outcome was evaluated with respect to packet delivery ratio, delay, routing load, and throughput with respect to simulation time.

Maddali [36] have introduced a unique multicast routing technique that adopts distributed mechanism using states of routing. The technique was originally made for heterogeneous routing and introduces a new node type called as core node. The study assumes that such core nodes have sufficient resources more than a normal sensor node. The study outcome was testified with respect to delay, latency, energy conservation factor, throughput, delay, packet delivery ratio, and overhead.

Sule et al. [37] have presented a multicast routing that works by on demand approach in wireless sensor network. The technique enhances the conventional clustering process to be used in multicasting and chooses an aggregator node to be the source of multicast routing. This mechanism also enhances the performance of group communication system. Study in similar direction was also carried out by Guo [38] and Gaddour [39].

Han et al. [40] have presented a technique that uses distributed approach for enhancing the throughput of multicast routing in sensor network. The authors have used network coding for this purpose that consider diversity of disjoint path. The technique develops dual directed acyclic graph. The technique also evaluates the complexity of the multicast routing where the study outcome is evaluated with respect to energy consumption, delay, packet loss rate, etc.

Study on multicast routing is also tried in security problems. Mani [41] have developed a multicast routing protocol which is meant to securing communication in wireless sensor network. The author have used public key cryptography for this purpose.

Oikonomou et al. [42] have presented a technique of multicast routing using IPv6. The author have introduced a multicasting mechanism which doesn't consider system states. Implemented on real-time motes, the study outcome was evaluated with respect to energy, packet arrival, delay, etc.

Hao et al. [43] have presented a study that addresses the energy dissipation problems in sensor network using multicast routing. The author have added on-demand characteristics for energy saving purpose. The study outcome was evaluated with respect to network lifetime.

Li et al. [44] have presented a unique technique of multicast routing over Internet-of-Things that integrates cloud with wireless sensor network. The technique also uses Hopfield neural network that yields better communication result.

Krishna and Doja [45] have used geographic multicast routing in various forms considering scalability, distributive, clustering etc. The study outcome was testified with respect to various QoS parameters to shows that hierarchical geographic multicasting routing is the appropriate one.

Han et al. [46] have presented a technique which addresses the scheduling problem of the multicast tree construction. The technique has used an approximation algorithm with polynomial time. Using graph theory, the author have presented their study to accomplish better delay performance.

Marchiori and Han [47] have presented a study where IPv6 has been used as case study of wireless sensor network. The technique uses bloom filter to minimize the rate of false positive. The study outcome shows enhanced packet delivery ratio, minimized latency and minimal utilization of radio resources.

Khan et al. [48] have discussed a technique that incorporates QoS over multicast, where the researcher utilizes the integer programming of linear kinds to reduce quantity of the nodes.

Mansouri and Wong [49] have presented a technique using coding flow for solving network lifetime maximization problem in sensor network. The study outcome shows presented technique better reduction in energy consumption.

The overall summary of above explained existing research works are represented in Table 3. 
TABLE III. SUMMARY OF EFFECTIVENESS IN EXISTING SYSTEM

\begin{tabular}{|c|c|c|c|c|}
\hline Author & Problem & Technique & Advantage & Limitation \\
\hline Piechowiak et al. [34] & - & $\begin{array}{l}\text { Discussion of topology control } \\
\text { techniques }\end{array}$ & $\begin{array}{l}\text { Theoretical discussion of } \\
\text { algorithm }\end{array}$ & $\begin{array}{l}\text {-No discussion of } \\
\text { benchmarking }\end{array}$ \\
\hline Thenral and Sikamani [35] & $\begin{array}{l}\text { Selection of intermediate node } \\
\text { in multicast routing }\end{array}$ & $\begin{array}{l}\text { Condition of angle between } \\
\text { nodes to be within } 60 \%\end{array}$ & $\begin{array}{l}\text {-Good QoS outcomes } \\
\text {-reduced overhead }\end{array}$ & $\begin{array}{l}\text {-Reduced applicability to large } \\
\text { network. } \\
\text {-Doesn't support dynamic } \\
\text { topology }\end{array}$ \\
\hline Maddali [36] & Network performance & $\begin{array}{l}\text { Core node to balance network } \\
\text { load }\end{array}$ & $\begin{array}{l}\text {-Good QoS outcomes } \\
\text {-benchmarked outcomes }\end{array}$ & $\begin{array}{l}\text {-Doesn't support dynamic } \\
\text { topology } \\
\text {-No discussion of algorithm } \\
\text { complexity }\end{array}$ \\
\hline $\begin{array}{l}\text { Sule et al. [37], Guo [38], } \\
\text { Gaddour [39] }\end{array}$ & Multicasting, Broadcasting & Cluster based multicast routing & -Low latency & $\begin{array}{l}\text {-No extensive analysis of } \\
\text { outcomes to prove the claim }\end{array}$ \\
\hline Mani [41] & Security & Public key cryptography & -Lower key size & $\begin{array}{l}\text {-Doesn’t support dynamic } \\
\text { topology }\end{array}$ \\
\hline Oikonomou et al. [42] & $\begin{array}{l}\text { Energy and bandwidth } \\
\text { enhancement }\end{array}$ & IPv6 routing & -Minimize delay & $\begin{array}{l}\text {-Doesn't support dynamic } \\
\text { topology, } \\
\text {-No cost minimization policy }\end{array}$ \\
\hline Hao et al. [43] & Energy & On-demand approach & -Simple implementation & $\begin{array}{l}\text {-Limits optimization } \\
\text {-No discussion of } \\
\text { benchmarking }\end{array}$ \\
\hline Li et al. [44] & Complexity of routing & Hop Neural network & -Reduced complexity & $\begin{array}{l}\text {-No discussion of } \\
\text { benchmarking } \\
\text {-Doesn't support dynamic } \\
\text { topology }\end{array}$ \\
\hline Krishna and Doja [45] & $\begin{array}{l}\text { Comparative analysis of } \\
\text { multicast routing }\end{array}$ & Performance study & $\begin{array}{l}\text {-Hierarchical approach is } \\
\text { suitable for multicast routing }\end{array}$ & $\begin{array}{l}\text {-No discussion of } \\
\text { benchmarking } \\
\text {-Doesn't support dynamic } \\
\text { topology } \\
\text {-No discussion of optimization }\end{array}$ \\
\hline Han et al. [46] & Scheduling & Approximation algorithm & -Lowered delay & $\begin{array}{l}\text {-Doesn't support dynamic } \\
\text { topology }\end{array}$ \\
\hline Marchiori and Han [47] & Memory usage & Bloom filters & $\begin{array}{l}\text {-Lower radio usage } \\
\text {-addresses memory problem }\end{array}$ & $\begin{array}{l}\text {-Time complexity not } \\
\text { presented }\end{array}$ \\
\hline Khan et al. [48] & QoS in routing & Integer programming approach & -Good throughput & $\begin{array}{l}\text {-Doesn’t support dynamic } \\
\text { topology }\end{array}$ \\
\hline Mansouri and Wong [49] & Energy consumption & Coding flow & -Energy efficient & -No discussion on cost. \\
\hline
\end{tabular}

\section{RESEARCH GAP}

This section presents the research gap that is explored after reviewing the existing literatures. Following are the research gaps:

a) Few studies towards optimization: There is few standard research manuscript using bio-inspired optimization techniques. Although, there are recent discussion [50]-[54] related to usage of advanced optimization principle based on bio-inspired techniques, but still the success factor of bioinspired algorithms are not seen in multicast routing in sensor network.

b) Lack of complexity analysis: An algorithm complexity is determined with space and time factor, which is not much seen in existing studies towards multicast routing.

c) Non-supportability of dynamic topology: With sensor network increasing being used in Internet-of-Things, Reconfigurable network, dynamic topology is imperative to be considered. However, majority of the studies in multicast routing is focused on static topology where it can never cater up the communication need of uncertain and dynamic networks.

d) Few studies towards cost minimization: The term cost will represent amount of resources required to do a particular task. There are less number of studies which has focused on minimizing cost using mathematical modelling or analytical modelling in sensor network. Moreover retaining the overall balance between QoS parameters and scalability is another problem yet to be solved.

e) Few mathematical modelling: Deterministic modelling is not possible to be used in investigating multicast routing problem. Hence, probabilistic models are only alternatives. There is a need of a discrete mathematical modelling that can overcome the cumulative complexities of the multicast routing in sensor network.

The above studied research gaps are necessary to be considered in any further research towards enhancing multicast routing in sensor network. 


\section{PROPOSED LINE OF RESEARCH}

After reviewing the research gap in the previous section, it is quite obvious that study towards enhancing multicast routing protocol is still in infancy stage when it comes to optimization. This section presents a brief of the proposed line of research in order to address the research gap identified in this review.

\section{A. Optimizing Multicast Routing using Novel Bio-Inspired Stochastic Algorithm}

The prime purpose of this algorithm will be spoken to the optimization issue of multicast routing in wireless sensor network. A novel probabilistic-based routing can be developed for routing along with evolving up with a new bio-inspired algorithm with stochastic feature in order to solve the binary optimization problem. Following are further brief of this technique:

- Problem identified: This segment of the proposed work will focus on the delay and overhead problems in multicast routing.

- Proposed methodology: An empirical research methodology can be adopted that initially designs a simple bio-inspired framework with basic components e.g. velocity, position, fitness factor, etc. The novel framework should have the ability to achieve binary optimization for selection in the node for performing multicast routing.

- Anticipated outcomes: Faster speed of convergence, lower overhead and complexity, high throughput. The study outcome should have lower delay and data loss with faster response time.

\section{B. Minimizing Cost of Multicast Routing using Novel Combinatorial Optimization Approach}

The prime purpose of this study should be to address the computational complexity associated with the sensor that executes multicast routing protocol. Following are further brief of this technique:
- Problem Identified: The study will emphasize on minimizing the cost of multicast routing during multimedia communication system.

- Proposed methodology: A novel analytical technique can be developed that will apply enhanced version of particle swarm optimization along with combinatorial optimization technique for optimizing better form of search for minimum cost. Along with this a completely new bio-inspired algorithm can be developed based on new cognitive skills of master and disciple.

- Anticipated outcomes: The study outcome will be testified using convergence behaviour of the technique. Emphasis should be also given to the response and QoS parameters of sensor network.

\section{Cost-Based Modelling of Multicast Routing for Leveraging Dynamic Topology}

This section will introduce a novel model that performs multicast management for supporting mobility factor in sensor network.

- Problem identified: The study will address multicast management problems in presence of dynamic topology.

- Proposed methodology: The study will use analytical modelling that can ensure faster association and disassociation of a mobile node to receive message in order to reduce the cost involved in signaling process in multicast routing. It will use tree concept to ensure that further cost is minimized even after adopting mobility performance study.

- Anticipated Outcomes: The anticipated outcome of the study is to highly reduced delay, overhead, and bandwidth consumption.

The indicative architecture is highlighted in Fig. 7.

\begin{tabular}{|c|c|c|c|c|c|c|c|c|}
\hline \multicolumn{3}{|c|}{$\begin{array}{l}\text { Optimizing Multicast Routing using Novel } \\
\text { Bio-Inspired Stochastic Algorithm }\end{array}$} & \multicolumn{2}{|c|}{$\begin{array}{l}\text { Minimizing Cost of Multicast } \\
\text { Routing using Novel } \\
\text { Combinatorial Optimization } \\
\text { Approach } \\
\end{array}$} & \multicolumn{3}{|c|}{$\begin{array}{c}\text { Cost-based Modelling of Multicast Routing for } \\
\text { Leveraging Dynamic Topology }\end{array}$} & $\frac{0}{\frac{0}{0}}$ \\
\hline \multicolumn{3}{|c|}{ 1. Optimization } & \multicolumn{2}{|c|}{ 2. Minimizing Cost } & \multicolumn{3}{|c|}{ 3. Multicast Management } & \\
\hline \multirow{5}{*}{ 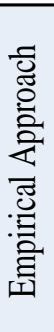 } & $\begin{array}{l}\text { Novel Bio- } \\
\text { Inspired }\end{array}$ & Velocity Update & \multirow{5}{*}{ 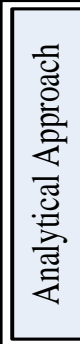 } & \multirow{2}{*}{$\begin{array}{c}\text { Enhanced } \\
\text { Particle Swarm } \\
\text { Optimization }\end{array}$} & \multirow{5}{*}{ 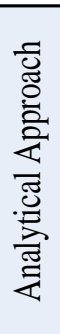 } & \multicolumn{2}{|c|}{ faster association / disassociation } & \\
\hline & $\begin{array}{l}\text { Stochastic } \\
\text { Algorithm }\end{array}$ & Position Update & & & & \multirow[t]{2}{*}{$\begin{array}{l}\text { Efficient packet } \\
\text { transmission }\end{array}$} & $\begin{array}{l}\text { Reduce } \\
\text { signaling }\end{array}$ & לָּ \\
\hline & \multicolumn{2}{|c|}{ Formulation of $M R P$} & & & & & cost & \\
\hline & \multicolumn{2}{|c|}{ Forming Fitness Function } & & combinatorial & & \multirow{2}{*}{\multicolumn{2}{|c|}{$\begin{array}{c}\text { Novel multicast management } \\
\text { Architecture }\end{array}$}} & \\
\hline & \multicolumn{2}{|c|}{ Form new Pruning Process } & & & & & & \\
\hline \multicolumn{2}{|c|}{$\begin{array}{c}\text { Faster speed of } \\
\text { convergence }\end{array}$} & $\begin{array}{l}\text { lower overhead } \\
\text { and complexity }\end{array}$ & & $\begin{array}{l}\text { convergence } \\
\text { behaviour }\end{array}$ & & \multirow{2}{*}{\multicolumn{2}{|c|}{$\begin{array}{l}\text { reduced delay, overhead, and } \\
\text { bandwidth consumption. }\end{array}$}} & \\
\hline \multicolumn{3}{|c|}{ high throughput } & \multicolumn{2}{|c|}{ QoS parameters } & & & & \\
\hline
\end{tabular}

Fig. 7. Indicative architecture for proposed line-of-research. 


\section{CONCLUSION}

Wireless sensor network is one of the frequently visited topic when it comes to research on wireless network. Till date, there has been lots of improvement to this that resulted in adoption of sensor nodes to play a core role in futuristic technologies, e.g. Internet-of-Things, etc. The routing protocols are the only tool to ensure that sensor node does the task of data aggregation effectively in presence of their resource constraints. This paper has discussed about the multicast routing protocols and their effectiveness in using it in sensor network. As multicast routing was originally meant for mobile adhoc networks, so still it has not received full fledge adoption in sensor network owing to unsolved problems e.g. message overhead, complexity, higher delay, etc. Our review statistics states that in last five years there has been less number of standard research manuscript noticed to discuss about it.

The present scenario of implementations is more symptomatic in nature, which will mean that it addresses some specific problem leaving other problem unattended. That leads to lesser reliable framework that couldn't be acknowledged for future research work. Moreover, we didn't find much work in optimization in this regards. We strongly believe that bioinspired algorithms have potential capabilities in solving the cumulative problems associated with multicast routing. But, there are almost no IEEE transaction papers published in last 5 years that has used novel bio-inspired optimization principle to upgrade the multicast routing performance in order to minimize cost. Hence, we present our future work in the form of proposed line-of-research with clear visualization of novel framework that will going to implement in coming days.

\section{REFERENCES}

[1] H. M. A. Fahmy, Wireless Sensor Networks: Concepts, Applications, Experimentation and Analysis, Springer, 03-Apr2016.

[2] M. S. Obaidat, S. Misra, Principles of Wireless Sensor Networks, Cambridge University Press, 2014.

[3] S. K. Sarkar, Wireless Sensor and Ad Hoc Networks Under Diversified Network Scenarios, Artech House, 01-Jan-2012.

[4] F. Hu, X. Cao, Wireless Sensor Networks: Principles and Practice, CRC Press, 06-May-2010.

[5] J. Zheng, A. Jamalipour, Wireless Sensor Networks: A Networking Perspective, John Wiley \& Sons, 2009.

[6] J. N. Al-Karaki, A. E. Kamal, "Routing Techniques in Wireless Sensor Networks: A Survey", IEEE Journal of Wireless Communications, Vol.11, Iss.6, pp.6-28, 2004.

[7] J. Wang, J-U Kim, L. Shu, Y. Niu, and S. Lee, "A Distance-Based Energy Aware Routing Algorithm for Wireless Sensor Networks", Sensors, vol.10, pp.9493-9611, 2010.

[8] C. Li, H. Zhang, B. Hao and Jiandong Li, "A Survey on Routing Protocols for Large-Scale Wireless Sensor Networks", Sensors, vol.11, pp.3498-3526, 2011.

[9] G. K. Nigam, C. Dabas, "A Survey on Protocols and Routing Algorithms for Wireless Sensor Networks", Proceedings of the World Congress on Engineering and Computer Science, 2015.

[10] E. Rosenberg, "A Primer of Multicast Routing", Springer Science \& Business Media, 2012.

[11] R. Vaishampayan and J. J. Garcia-Luna-Aceves, "Efficient and robust multicast routing in mobile ad hoc networks", IEEE International Conference on Mobile Ad-hoc and Sensor Systems, pp. 304-313, 2004.

[12] E. M. Royer and C. E. Perkins, "Multicast operation of the ad hoc on demand distance vector routing protocol", Proceedings of the 5th annual ACM/IEEE International Conference on Mobile Computing and Networking, pp. 207-218, 2000.

[13] S-J Lee, W Su, and M. Gerla, "On-demand multicast routing protocol in multihop wireless mobile networks", Mobile Networks and Applications, Vol. 7, No. 6, pp. 441-452, 2002.

[14] M. Ge, S. V. Krishnamurthy and M. Faloutsos, "Application versus network layer multicasting in ad hoc networks: the ALMA routing protocol", Ad Hoc Networks, Vol. 4, No. 2, pp. 283-300, 2006

[15] A. Detti, N. B. Mezzi and C. Loreti, "Overlay, Boruvka-based, adhoc multicast protocol: description and performance analysis", IEEE International Conference on Communications, pp. 55455552,2007

[16] K. Verma, "Multicast Routing Protocols for Wireless Sensor Networks:A comparative study", International Journal of Computer Science and Innovation, no. 1, pp. 39-52, 2015.

[17] P. Aggarwal, R. Kumar, A. Bhardwaj, "Multicast Routing Protocols in Wireless Sensor Network", International Journal of Computer Science and Information Technologies, Vol. 4, Iss.1, pp. $216-219,2013$.

[18] A. Suruliandi and T. Sampradeepraj, "A Survey On Multicast Routing Protocols For Performance Evaluation In Wireless Sensor Network", Journal On Communication Technology: Special Issue On Communication And Health Monitoring Based Modeling And Simulation Using Wireless Sensor Networks, Volu.06, Iss.01, 2015.

[19] J. Kumari and Prachi, "A comprehensive survey of routing protocols in wireless sensor networks," IEEE 2nd International Conference on Computing for Sustainable Global Development, pp. 325-330, 2015.

[20] X. Liu, "Atypical Hierarchical Routing Protocols for Wireless Sensor Networks: A Review," IEEE Sensors Journal, vol. 15, no. 10, pp. 5372-5383, Oct. 2015.

[21] A. Modirkhazeni, N. Ithnin and O. Ibrahim, "Secure Multipath Routing Protocols in Wireless Sensor Networks: A Security Survey Analysis," IEEE Second International Conference on Network Applications Protocols and Services, pp. 228-233, 2010.

[22] N. A. Pantazis, S. A. Nikolidakis and D. D. Vergados, "EnergyEfficient Routing Protocols in Wireless Sensor Networks: A Survey," IEEE Communications Surveys \& Tutorials, vol. 15, no. 2, pp. 551-591, 2013

[23] Q. Zia, "A Survey of Data-Centric Protocols for Wireless Sensor Networks", Journal of Computer Science \& Systems Biology, vol.8, pp.127-131, 2015.

[24] K. Iwanicki and M. van Steen, "On hierarchical routing in wireless sensor networks," IEEE International Conference on Information Processing in Sensor Networks, pp. 133-144, 2009.

[25] H. Cho, Y. Baek, "Location-Based Routing Protocol for Energy Efficiency in Wireless Sensor Networks", Springer- Embedded and Ubiquitous Computing - EUC 2005 Workshops, vol.3823, pp.622-631, 2005.

[26] Y. Yu, R. Govindan, D. Estrin, "Geographical and Energy Aware Routing: a recursive data dissemination protocol for wireless sensor networks", Technical report ucla/csd-tr-01-0023, UCLA Computer Science Department, 2001.

[27] A. Sheth, B. Shucker and R. Han, "VLM2: a very lightweight mobile multicast system for wireless sensor networks," IEEE Wireless Communications and Networking, 2003. pp. 1936-1941 vol.3, 2003.

[28] A. Okura, T. Ihara and A. Miura, "BAM: branch aggregation multicast for wireless sensor networks," IEEE International Conference on Mobile Adhoc and Sensor Systems Conference, 2005.

[29] Y. Min, Y. Bo, H. Peng, M. Dilin and G. Chuanshan, "A optimized distributed multicast routing protocol for wireless sensor network," IEEE Workshop on Wireless Mesh Networks, pp. 166169, 2006.

[30] J. A. Sanchez, P. M. Ruiz and I. Stojmnenovic, "GMR: Geographic Multicast Routing for Wireless Sensor Networks," 
IEEE Communications Society on Sensor and $\mathrm{Ad} \mathrm{Hoc}$ Communications and Networks, pp. 20-29, 2006.

[31] S. M. Das, H. Pucha, Y. C. Hu, "Distributed Hashing for Scalable Multicast in Wireless Ad Hoc Networks", Technical Reports of Purdue University, 2006.

[32] D. Koutsonikolas, S. Das, Y. C. Hu, I. Stojmenovic, "Hierarchical Geographic Multicast Routing for Wireless Sensor Networks", IEEE International Conference on Sensor technologies and applications, pp.347-354, 2007.

[33] J. Pu, X. Tang, F. Wang, and Z. Xiong, "A Multicast Routing Protocol with Pruning and Energy Balancing for Wireless Sensor Networks", International Journal of Distributed Sensor Networks, , 2012.

[34] M. Piechowiak, K. Stachowiak, and T. Bartczak, "Multicast Connections in Wireless Sensor Networks with Topology Control", Journal of Telecommunication and information technology, 2016.

[35] B. Thenral and K. T. Sikamani, "AMRA: Angle based Multicast Routing Algorithm for Wireless Mesh Networks", Indian Journal of Science and Technology, Vol 8, Iss.13, 2015.

[36] B. K. Maddali, "Core network supported multicast routing protocol for wireless sensor networks", IET Wireless Sensor Systems, 2015.

[37] C. Sule, P. Shah, K. Doddapaneni, O. Gemikonakli, "On demand Multicast Routing in Wireless Sensor Networks", International Conference on Advanced Information Networking and Applications Workshops, 2014.

[38] M. H. Guo, J-F Lin, "The Improved WCMRP Protocol for Mobile Wireless Sensor Networks", Journal Of Communications, vol. 6, no. 2, 2011.

[39] O. Gaddour, A. Koubaak, O. Cheikhrouhou, M. Abid, "Z-Cast: A Multicast Routing Mechanism in ZigBee Cluster-Tree Wireless Sensor Networks", IEEE International Conference on Distributed Computing Systems Workshops, pp.171-179, 2010.

[40] Z-J Han, R-C Wang, and F. Xiao, "A Multicast Algorithm for Wireless Sensor Networks Based on Network Coding", Hindawi Publishing Corporation International Journal of Distributed Sensor Networks, 2014.

[41] D. M. Mani, "Secure Multicasting for Wireless Sensor Networks", International Journal of Computer Science and Network Security, Vol.14, No.11, November 2014.

[42] G. Oikonomou, I. Phillips, T. Tryfonas, "IPv6 Multicast Forwarding in RPL-Based Wireless Sensor Networks", Springer Journal of Wireless Personal Communication, 2013.
[43] J. Hao, G. Duan, B. Zhang, C. Li, "An Energy-Efficient OnDemand Multicast Routing Protocol for Wireless Ad Hoc and Sensor Networks", IEEE Globecom-Wireless Networking Symposium, 2013.

[44] G. Li, D. G. Zhang, K. Zheng, X. C. Ming, Z. H. Pan, K. W. Jiang, "A Kind of New Multicast Routing Algorithm for Application of Internet of Things", Elsevier-ScienceDirect, Journal of Applied Research and Technology, Vol.11, Iss.4, pp.578-585, August 2013.

[45] M. B. Krishna, and M. N. Doja, "Analysis of tree-based multicast routing in wireless sensor networks with varying network metrics", International Journal Of Communication Systems, 2012.

[46] K. Han, Y. Liu, and J. Luo, "Duty-Cycle-Aware Minimum-Energy Multicasting in Wireless Sensor Networks", IEEE/ACM Transactions On Networking, 2012.

[47] A. Marchiori and Q. Han, "PIM-WSN: Efficient Multicast for IPv6 Wireless Sensor Networks", IEEE International Symposium World of Wireless, Mobile and Multimedia Networks, pp.1-6, 2011

[48] M.A. Khan, G.A. Shah, M.Sher, "A QoS based multicast communication framework for wireless sensor actor network", International Journal of Innovative Commputing, information, and Control, vol.7, No.12, 2011.

[49] Vahid Shah-Mansouri, Vincent W.S. Wong, Lifetime-Resource Tradeoff for Multicast Traffic in Wireless Sensor Networks, IEEE Transactions on Wireless Communications (Volume:9, Issue: 6 ), pp.1924-1934, 2010.

[50] Md. Akhtaruzzaman Adnan, M. A. Razzaque, I. Ahmed, and I. F. Isnin, "Bio-Mimic Optimization Strategies in Wireless Sensor Networks: A Survey", Sensors, pp.299-345, 2014.

[51] M. A. Alsheikh, S. Lin, D. Niyato and H-P Tan, "Machine Learning in Wireless Sensor Networks: Algorithms, Strategies, and Applications", IEEE Communications Surveys \& Tutorials, Vol.16, Iss.4, pp.1996-2018, 2014.

[52] R. Aryaa, S.C. Sharmab, "Analysis and optimization of energy of sensor node using ACO in wireless sensor network", ElsevierScienceDirect, International Conference on Advanced Computing Technologies and Applications, Procedia Computer Science, vol.45, pp.681-686, 2015.

[53] S. K. Goudos, "Evolutionary Algorithms for Wireless Communications, A Review of the State-of-the art", IntechOpen, 2014.

[54] Y. H. Robinson and M. Rajaram, "Energy-Aware Multipath Routing Scheme Based on Particle Swarm Optimization in Mobile Ad Hoc Networks", Hindawi Publishing Corporatio, e-Scientific World Journal, 2015. 